\title{
Sobre Kant, Putnam y el realismo interno
}

\author{
About Kant, Putnam and internal realism
}

\author{
Luisa POSADA KUBISSA
}

Universidad Complutense de Madrid

Recibido: 05-07-2011

Aceptado: 14-11-2011

\section{Resumen}

Hablar de las herencias del pensamiento moderno y referirse a Kant resulta una obviedad. Pero cuando Putnam asevera que Kant fue "el primer realista interno" parece de suyo tomarlo en consideración. Centrándonos tan sólo en la fase de este realismo interno putnamiano -y en particular tal como se expresa en Razón, verdad e historia-, este trabajo se propone detectar algunos de los lugares textuales de la Crítica de la razón pura que avalan esa afirmación y la dotan de sentido. Qué entienden ambos textos por racionalidad y por verdad nos guiará a la hora situar dónde ambos pensadores, más allá de la distancia teórica e histórica, vienen a encontrase.

Palabras clave: Esquema conceptual, esquematismo trascendental, justificación idealizada, realismo interno, realismo metafísico

\begin{abstract}
To speak about the inheritances of modern thought and to refer to Kant is something obvious. But when Putnam assures that Kant was "the first internal realist", it is important to take it into account. Focusing only in the phase of this internal
\end{abstract}


Putnamian realism- and particularly exactly as it is expressed in Reason, Truth and History-this work tries to detect some of the places in the Critique of Pure Reason which could back up this statement and give it sense. What both texts understand by rationality and truth will guide us to the place where - beyond the theoretical and historical distance - both philosophers coincide.

Key words: Conceptual scheme, transcendental schematic, idealized justification, internal realism, metaphysical realism.

\section{Sobre el realismo interno}

No se trata aquí de analizar la evolución del pensamiento de Putnam y, ni tan siquiera, de centrarse en aquellos momentos del mismo que han supuesto cambios decisivos de orientación. Lo que nos proponemos es mucho más modesto y, a la vez, más concreto: partir del denominado realismo interno, aun a sabiendas de que tal posición fue también superada por su creador. Y partir de ahí, para comprender en última instancia sus conexiones con la filosofía del uso teórico de la razón en Kant, conexiones de las que Putnam era plenamente consciente.

Abandonar el realismo metafísico no pasa, para Putnam, por abandonar el realismo ni por situarse en una suerte de posición relativista. Ahora la verdad viene a entenderse como "justificación idealizada", de tal manera que, en condiciones ideales epistemológicamente hablando, la verdad sería "independiente de la justificación aquí y ahora, no independiente de toda justificación"; y además será "estable o "convergente"”'. Pero, ¿qué será entonces la verdad o cómo definirla?: "Desde la perspectiva internalista, la 'verdad' es una especie de aceptabilidad racional (idealizada) - una especie de coherencia ideal de nuestras creencias entre sí y con nuestras experiencias, considerándolas como experiencias representadas en nuestro sistema de creencias- y no una correspondencia con 'estados de cosas' independientes de la mente o del discurso. No existe un punto de vista como el del Ojo de Dios que podamos conocer o imaginar con provecho" 2 .

Sin que se pretenda aquí forzar comparación alguna, no es fácil resistirse a poner en relación esta afirmación putnamiana con algunas de las afirmaciones de Kant en su Crítica de la razón pura. Valga como muestra un botón: así cuando Kant escribe que "Lo que sean las cosas en sí mismas no lo sé, ni necesito saberlo, ya que no se me puede presentar una cosa más que en el fenómeno 3 ".

\footnotetext{
${ }^{1}$ H. Putnam. Reason, Truth and History. Cambridge: Cambridge University Press /Razón, verdad e historia. Madrid: Tecnos, 1988, 65.

2 H. Putnam. Op. cit., 59.

3 Kant. Crítica de la razón pura. Madrid: Ediciones Alfaguara, 1978 (1ª ed.), 286, A277, B333. Citaremos a partir de ahora esta obra kantiana como $\mathrm{KrV}$.
} 
Para Putnam el realismo metafísico, el "Ojo de Dios", se aleja de una noción coherente de realismo. Porque finalmente aboca al sujeto a aceptar que lo que él toma por realidad no es otra cosa que lo que la ciencia dice que es real. De este modo, el volverse a un realismo interno no debe entenderse como una forma de desentenderse del realismo, sino antes bien de fundamentarlo. Y la primera exigencia para ello pasa por relacionar hechos y valores. Así, en Razón, verdad e historia encontramos esta tesis especialmente dirigida a la relevancia que esta concepción tiene para la propia noción de verdad: “(...) hecho (o verdad) y racionalidad son nociones interdependientes. Un hecho es algo que es racional creer. Así, pues, "racionalmente aceptable" y "verdad" son nociones interdependientes. (...) ser racional implica tener un criterio de relevancia además de un criterio de racionalidad, y que en nuestro criterio de relevancia están supuestos todos nuestros valores. La decisión de que una imagen del mundo es verdadera (o verdadera según nuestros conocimientos actuales o "tan verdadera como la que más") y las respuestas a las cuestiones relevantes (así como nuestra capacidad para responderlas) revelan todo nuestro sistema de compromisos valorativos, sobre el cual descansan. Un ser sin valores tampoco tiene hechos"4.

Por tanto, Putnam toma distancia de la dicotomía entre hecho y valor, que el realismo metafísico presenta como central para separar la ciencia de cualquier otro tipo de conocimiento. Para el realismo metafísico la ciencia sólo entiende de hechos y estos son independientes del esquema conceptual del sujeto que conoce. El realismo interno quiere desvelar cómo esta posición es una ficción insostenible, ya que además requiere de un punto de vista del "Ojo de Dios" para acreditarse.

Que la ciencia nos ofrezca representaciones que parecen más valiosas puede argumentarse porque "el que 'la ciencia busca descubrir la verdad' sólo puede significar que la ciencia constituye una imagen del mundo que, en el límite ideal, satisface ciertos criterios de aceptabilidad racional" $5, \mathrm{Y}$ estos criterios de aceptabilidad racional nos permiten elaborar una imagen teórica del "mundo empírico"6. De manera que ahora Putnam puede sostener que "Lo que quiero resaltar aquí es la otra cara de la moneda, la dependencia del mundo empírico con respecto a nuestros criterios de aceptabilidad racional. Lo que trato de afirmar es que hasta para tener un mundo empírico debemos tener criterios de racionalidad, y que éstos revelan parte de nuestra concepción de una inteligencia especulativa óptima. En resumen, estoy afirmando que el "mundo real" depende de nuestros valores (y, una vez más, también al contrario)"7.

\footnotetext{
${ }^{4}$ H. Putnam. Op. cit., 199.

5 H. Putnam. Op. cit., 134.

${ }^{6}$ H. Putnam. Op. cit., 138.

${ }^{7}$ H. Putnam. Op. cit., 138.
} 
Comprender esta co-implicación entre mundo real y valores nos acerca al "florecimiento cognitivo humano" $\mathrm{y}$, con ello, al florecimiento humano total o Eudaemonia ${ }^{8}$. Y tal Eudaemonia es sólo posible si consideramos la actividad racional "orientada por la idea de lo bueno"; más en concreto, Putnam asevera que "Una vez privados de la vieja idea realista de la "verdad como correspondencia" y de la idea positivista bajo cuya óptica la justificación se fija mediante "criterios" públicos, nos hemos quedado con la necesidad de considerar nuestra búsqueda de mejores concepciones de la racionalidad como una actividad intencional y humana, la cual, como cualquier actividad que se alce por encima del hábito y del mero seguimiento de la inclinación o de la obsesión, está orientada por la idea de lo bueno"9.

Hay, por tanto, una presuposición de que lo bueno pueda ser objetivo y, en cualquier caso, referencia de nuestra actividad racional, que recuerda al pasaje de la Crítica de la razón pura en el que Kant plantea cuál es "El objetivo final del uso puro de nuestra razón”. Y ahí se nos dice que "(...) el objetivo último de una naturaleza que nos ha dotado sabiamente al construir nuestra razón no apunta en realidad a otra cosa que al aspecto moral" 10 . Y es sólo esta orientación de la razón pura la que permite hablar de una ley moral, que consiste en "la dignidad de ser feliz"11.

No seguiremos adelantando las comparaciones entre el realismo interno y la Crítica de la razón pura, pues de momento nos interesa clarificar aquella concepción de Putnam que nos guiará después hasta Kant. Sí decir que, tanto uno como otro, parecen tener claro que la ciencia nos proporciona el mejor conocimiento posible. En términos putnamianos repitamos que "hasta para tener un mundo empírico debemos tener criterios de racionalidad" 12 . Y esto es tanto como decir que no se trata de caer en un relativismo sin más, sino que la objetividad científica se construye y lo es para nosotros ${ }^{13}$. De este modo la verdad será “ (...) una especie de aceptabilidad racional (idealizada) - una especie de coherencia ideal de nuestras creencias entre sí y con nuestras experiencias, considerándolas como experiencias representadas en nuestro sistema de creencias- y no una correspondencia con "estados de cosas" independientes de la mente o del discurso" 14.

Ahora bien, si esto es así, parece claro que nuestra idea de verdad no tiene un correlato fuera de la propia historia en la que se sitúa, esto es, que no podemos hablar de verdad en términos absolutos. Esto, no obstante, no significa para Putnam que no podamos referir a una verdad ideal, a "un concepto-límite de verdad

\footnotetext{
${ }^{8}$ H. Putnam. Ibid.

9 H. Putnam. Op. cit, 140.

10 Kant. KrV, 627, A 801, B 829.

11 Kant. $K r V$, 631, A 806, B 834.

12 H. Putnam. Op. cit., 138.

13 H. Putnam. Op.cit., 148 y ss.

14 H. Putnam. Op. cit., 59.
} 
ideal"15, que quiere alejarse del relativismo. Así, la verdad no es aceptabilidad racional aquí y ahora, sino aceptabilidad racional en relación a ese límite ideal. De este modo, la objetividad se evalúa por la aceptabilidad racional, que implica valores tales como la coherencia, la simplicidad o la capacidad de predicción. Y aque1la se transforma tanto como se transforman estos. Contra el intento de dar una única descripción de los hechos $\mathrm{y}$, a la vez, contra una posición relativista extrema, Putnam apuesta por un realismo que supere la concepción del realismo metafísico por medio de una concepción de cómo se representa simbólicamente el mundo que apela a la objetividad fundada en los valores y en la interacción con los demás.

\section{Sobre Kant y el realismo interno}

Richard Rorty escribe en la introducción a Objetividad, realismo y verdad, que el viejo debate entre realismo e idealismo ha quedado aparcado definitivamente en el siglo precedente: "En 1900 lo contrario del realismo era todavía el idealismo", pero "en nuestros días, lo contrario del realismo es llamado, simplemente, 'antirrealismo""16. Pero, dando un paso más allá, propone que este término también es ambiguo, pues por un lado remite a un enfrentamiento con aquellos filósofos que sostienen que la mente o el lenguaje contienen representaciones de la realidad; $y$, por otro lado, apunta hacia el antirrepresentacionalismo, esto es, a aquella posición que niega el realismo por cuanto niega la noción de representación misma. Desde esta distinción conceptual, Rorty va a abogar por que el problema filosófico se desgaje del marco de la oposición realismo/ antirrealismo, que sigue preso de la visión representacionalista del conocimiento: el problema está entre quienes defienden la utilidad y el sentido de la representación y quienes, como él mismo, se sitúan en la óptica del antirrepresentacionalismo ${ }^{17}$.

También Hilary Putnam, como Rorty, ha visto en la filosofía moderna, que sitúa el conocimiento directo en las representaciones, una influencia filosófica de la que sólo cabe desembarazarse. Pero, frente a Rorty, Putnam no entiende que esta crítica al representacionalismo suponga descalificar el realismo: no al menos la perspectiva de un realismo que, contra el propio Rorty, no tiene por qué entenderse al modo de la herencia filosófica moderna, como aquella visión que penetra en lo que realmente es, en lo en sí. Frente a esta concepción del realismo, presa del modelo tradicional, Putnam opone una comprensión del mismo desde una comprensión de

\footnotetext{
15 H. Putnam. Op. cit., 213.

16 R. Rorty. Objectivity, Relativism, and Truth. Philosopical Papers I, Cambridge: Cambridge University Press, 1991, pp. 5 y ss. I Objetividad, relativismo y verdad. Escritos filosóficos I, Barcelona: Paidós, 1996.

17 R. Rorty. Objetividad, relativismo y verdad. Escritos filosóficos I, 15 y ss.
} 
la realidad indisociable del nosotros que la piensa, imbricada con el esquema conceptual desde el que se hace posible como realidad. De modo que la crítica al realismo en Rorty se ve atrapada, para Putnam, en la misma concepción moderna, que quiere hacer de la realidad lo en sí, independiente y ajeno de los conceptos con los que es aprehendida.

Ahora bien, si "la mente y el mundo construyen conjuntamente la mente y el mundo" 18 , la crítica de Rorty es desacertada, por cuanto es desacertado su diagnóstico de qué sea el realismo. No se trata de que podamos ir más allá de la mente y evaluar cómo se ajustan o no nuestros conceptos a una realidad en sí, y tal planteamiento es directamente heredero de una concepción moderna clásica que defiende una visión representacionalista de cómo percibimos: a saber, que las cualidades primarias de los objetos provocan en nosotros una imagen o unos datos sensibles a partir de los cuales inferimos la existencia del mundo externo como causa del mismo. Pero si nos replanteamos este modelo, tenemos que volver a la cuestión de cómo nos representamos el mundo; y aquí hay que volver al espíritu del aserto putnamiano ya citado: que no hay mente y mundo sin mente y mundo.

Putnam rechaza, como Rorty, el representacionalismo propio de la filosofía moderna19; pero, a partir de ahí, su conclusión es que lo que está mal en esa concepción, y debe ser por tanto repensado, es la suposición de un realismo que aboga por un mundo en sí, independiente de nuestra conceptualización del mismo. No se trata de abandonar el realismo, sino en todo caso de abogar por un realismo no metafísico, y sí más directo. Desde este realismo es posible, contra Rorty, hablar de objetividad para un conocimiento que ya no pretende representar la realidad como ésta sea realmente en sí misma considerada ${ }^{20}$. Lo que se abandona definitivamente en esta nueva posición de Putnam es la tesis de la verdad como correspondencia.

No se trata ahora de entrar en la consideración del denominado realismo interno de Putnam que, después de Razón, verdad e Historia, ha dado paso a un realismo más directo. Tampoco estamos aquí interesados en cómo o de qué manera se dio el paso de una fase a otra. Simplemente queremos resaltar la concepción de que la realidad lo es dentro de un esquema conceptual, de manera que no puede ni siquiera hablarse de realidad sin hablar a la vez de conocimiento; o dicho de otra manera de nuevo: que no hay mente sin mundo, ni mundo sin mente. Y es esta posición la que nos interesa subrayar en Putnam, para subrayar a la vez lo cercana que la misma se nos antoja de las posiciones kantianas, cuando se ocupa de la razón en su uso teórico. Podemos ilustrar esta afirmación a partir de la comparación de las propias palabras de Putnam con algunas de las que aparecen en la Crítica de la razón pura:

18 H. Putnam. Op. cit., 13.

19 H. Putnam. The Many Faces of Realism (The Paul Carus Lectures, Washington, 1985). La Salle, Ill.: Open Court /Las mil caras del realismo. Barcelona: Paidós, 1994, 13-14.

${ }^{20}$ H. Putnam. Op. cit., 13. 
'Los 'objetos' no existen independientemente de los esquemas conceptuales. Desmenuzamos el mundo en objetos cuando introducimos uno u otro esquema descriptivo, y puesto que tanto los objetos como los símbolos son internos al esquema descriptivo, es posible indicar cómo se emparejan" 21 ; comparemos este párrafo con el siguiente: "Las categorías son conceptos que imponen leyes a priori a los fenómenos y, consiguientemente, a la naturaleza como conjunto de todos los fenómenos" 22 . ¿Estamos ante una especie de kantismo que entiende trascendentalmente que los objetos se rigen por nuestros conceptos?

No se trata de simplificar, sin más, la posición de Putnam y convertirla en poco más que un remedo contemporáneo de la filosofía kantiana. De hecho, el propio Putnam se ha ocupado en más de una ocasión de señalar las insuficiencias del planteamiento kantiano; así, por ejemplo, cuando rechaza tajantemente la noción kantiana de "cosa en sí" 23 , o cuando critica la necesidad de la filosofía moral kantiana de mantener la idea de "noumena"24. Aun así, Putnam mismo se encarga también de aproximar a Kant a sus propias posiciones, cuando en Razón, Verdad e Historia escribe que "la mejor lectura de Kant consiste en considerarlo como el primer autor que propuso lo que he denominado la perspectiva 'internalista' o 'realista interna' con respecto a la verdad, pese a que Kant en ningún momento afirme explícitamente que lo esté haciendo"25. ¿Qué significa que Kant mantuvo un realismo interno?

$\mathrm{Al}$ ocuparse de lo que denomina el esquematismo trascendental en la Crítica de la razón pura - nada más comenzar el Libro segundo de la Analítica trascendental, que se ocupa de la Analítica de los principios-, Kant asegura que "En todas las subsunciones de un objeto bajo un concepto la representación de tal objeto tiene que ser homogénea con el concepto, es decir, éste tiene que incluir lo representado en el objeto que haya de subsumir, ya que esto es lo que significa la expresión: 'un objeto está contenido en un concepto'“26. Ésta será, por tanto, la cuestión a resolver: ¿cómo es posible la "subsunción" de los objetos en las categorías?; o, en otras palabras: ¿cómo es posible aplicar las categorías a los fenómenos?; o, expresado en términos putnamianos: ¿cómo se da la relación entre mente y mundo?

Kant va a hablar de un "tercer término", a caballo entre la categoría y el fenómeno, a la vez sensible e intelectual, que llama "esquema trascendental". Este esquema trascendental no es otro que el tiempo: "una determinación trascendental del tiempo guarda homogeneidad con la categoría (que constituye la unidad de esa determinación) en la medida en que es universal y en que está basada en una regla

\footnotetext{
21 H. Putnam. Razón, verdad e historia, 61.

22 Kant. KrV, 173, B 163.

${ }^{23}$ H. Putnam. Las mil caras del realismo, 87.

24 H. Putnam. Op. cit., 94.

25 H. Putnam. Razón, verdad e historia, 69.

${ }^{26}$ Kant. $K r V .$, 182, A137, B176.
} 
a priori. Y es igualmente homogénea con el fenómeno, en la medida en que el tiempo se halla contenido en toda representación empírica de la diversidad". De lo cual se concluye que "Será, pues, posible aplicar la categoría a los fenómenos por medio de la determinación trascendental del tiempo cuando tal aplicación permita, como esquema de los conceptos del entendimiento, subsumir los fenómenos bajo la categoría"27. Ya que el único rasgo en común a todo objeto de experiencia, incluido el yo empírico, es su ser en el tiempo, éste será al que corresponde la condición de ser el esquema trascendental. Y el tiempo se traduce en esquemas que, en tanto determinaciones a priori del tiempo, se corresponden con el orden de las categorías: la serie del tiempo para las categorías de cantidad; el contenido del tiempo para las de cualidad; la ordenación del tiempo, para las categorías de relación; y el conjunto del tiempo, para el caso de la modalidad 28 . Pero, más allá de esta cuádruple ordenación, lo que nos interesa resaltar aquí es que los esquemas son los que proporcionan a esos conceptos puros una relación con los objetos y, por tanto, una significación. Y, con ello, hacen también que las categorías no tengan más uso posible que su uso empírico, "ya que sirven tan sólo para someter los fenómenos a unas reglas universales de síntesis tomando como base una unidad necesaria a priori (en virtud de la necesaria unificación de toda conciencia en una apercepción originaria) y para adecuar así tales fenómenos a una completa conexión con la experiencia" 29

Esta idea kantiana del esquema trascendental no parece muy alejada de una concepción de la objetividad que la entiende como indisociablemente ligada al sistema conceptual desde el que se mantiene dicha objetividad: esto es tanto como decir que, aun admitiendo la existencia independiente de las cosas, éstas no son nada en sí con independencia del punto de vista o la perspectiva que las aborda. Estamos muy cerca de la concepción de Putnam - al menos del Putnam de Razón, verdad e historia- y no tan lejos de la del propio Kant.

Hablamos en Putnam de la relatividad conceptual o del realismo interno, que va a entender el conocimiento como constitución activa, de tal modo que el objeto sólo es posible en tanto objeto conocido por la actividad conceptual: no otra cosa encontramos también en la Crítica de la razón pura, cuando se nos hace saber que “(...) no se concede a la cosa sino lo contenido en su concepto" 30 . Y no se trata aquí de un aserto idealista, cosa de la cual ya quiere alejarse Kant explícitamente en su refutación del idealismo: se trata, antes bien, de esa relatividad conceptual que, en términos putnamianos, vendría a defender que no hay un "Ojo de Dios" que nos permita acceder a las cosas fuera de nuestra perspectiva de las mismas. Y de esta mane-

\footnotetext{
27 Kant. $K r V, 183$, A 139, B 178.

${ }^{28}$ Kant. $K r V$, 185-187, A142-145, B182-185.

29 Kant. $K r V, 188, \mathrm{~B} 185$.

30 Kant. $K r V$, 289, A281/B337.
} 
ra el objeto es constituido en la propia actividad conceptual, de tal manera que cabe decir ahora que "Objeto es aquello en cuyo concepto se halla unificado lo diverso de una intuición dada" 31 . O, en una versión donde más claramente se enfatiza cómo el concepto es actividad, leeríamos que "Objeto empero es aquello en cuyo concepto lo múltiple de una intuición dada es reunido"32. Esta concepción de los conceptos como capacidad o actividad reaparece en Putnam claramente, cuando se pregunta "Pero, ¿qué son los conceptos?": Y responde: "La razón decisiva para sostener que los conceptos no son representaciones mentales que se refieren intrínsecamente a las cosas es que ni siquiera son representaciones mentales. Los conceptos son símbolos que se usan de cierto modo (...) Y los símbolos no se refieren de por sí intrínsecamente a ninguna cosa" 33 . De donde Putnam concluye que "Hemos visto que poseer un concepto no consiste en poseer imágenes (...). Pues la imagen, si no está acompañada por la capacidad de actuar de cierta manera, es sólo imagen"34.

Ser sólo imagen no es, por tanto, suficiente para "poseer un concepto". Porque "Bajo el nombre de síntesis trascendental de la imaginación el entendimiento realiza, pues, dicho acto sobre el sujeto pasivo, sujeto del cual el mismo entendimiento constituye la facultad, y así decimos justificadamente que a través de ésta es afectado el sentido interno" 35 , con lo que "El entendimiento no encuentra, pues, en el sentido interno semejante combinación de la diversidad, sino que la produce afectándolo"36. Este "producir" expresa esa "capacidad de actuar" que no es otra cosa que el concepto como producción. Cabe entender, por tanto, que estamos ante la concepción de concepto como acción, en tanto que capacidad de actuar, y no como representación pasiva. No otra cosa parece expresarse al decir que "(:::) los conceptos son (al menos en parte) capacidades, y no cosas que acontecen en la mente"37.

Que tales capacidades se activan con ocasión de la experiencia con los objetos externos es algo que retiene la dimensión realista que tanto Putnam como Kant quieren subrayar. Porque "(Las categorías) se refieren de modo necesario y a priori a objetos de la experiencia porque sólo a través de ellas es posible pensar algún objeto de la experiencia"38. Sin objeto no hay concepto, pero sólo el concepto pone en acción la experiencia del objeto. Putnam, no menos que Kant, quiere evitar con estas tesis todo relativismo, en el que no tuviera cabida la idea de verdad: “(...) los

\footnotetext{
${ }^{31}$ Kant. $\operatorname{KrV} 157$, B 137.

32 Kant, I., Crítica de la razón pura. Versión española de Manuel García Morente y Manuel Fernández Núñez. México: Editorial Porrúa, 1976 ( $3^{\mathrm{a}}$ ed.), 82.

33 H. Putnam. Razón, verdad e historia, 30.

34 H. Putnam. Op. cit., 31.

35 Kant. $K r V, 167-8$, B 153.

36 Kant. $K r V, 168-9$, B 155.

37 H. Putnam. Razón, verdad e historia, 33.

38 Kant. $K r V, 126$, B 126.
} 
intentos relativistas de definir la verdad (...) conducen a una maraña de consecuencias contradictorias, solipsistas o de alguna manera inaceptables"39. Por ello, Putnam va a proponer la verdad como algo que guía nuestro conocimiento y a lo que aspiramos más allá de la justificación eventual del mismo: la verdad es inmanente a la cultura y a la vez la trasciende. La idea de la verdad como justificación idealizada es utilizada por Putnam como revulsivo contra lo que considera que es el relativismo rortyano. El problema de la verdad, el querer saber si nuestro conocimiento es o no verdadero, es para Putnam un problema que compete a la filosofía: "En una famosa carta a Marcus Herz, Kant señaló que el problema de cómo lo que hay en la mente puede ser una "representación" de lo que hay fuera de ella es el asunto más complejo de la filosofía" 40 ; para añadir a continuación que "Lo que los filósofos necesitan saber es qué es la representación. Su misión consiste en descubrir la "naturaleza" de la representación" 41 .De este modo, la investigación sobre la verdad se hace posible; $y$, después de todo, “(...) para un pragmático, un debate sobre la verdad obtendrá su fundamento de la explicación paralela de cómo llegar a esa verdad" 42 .

Sin ánimo de forzar parecidos, ni de hacer de la posición kantiana un remedo anticipado del pragmatismo, sí resulta sin embargo obligado recordar qué dice la Crítica de la razón pura de la idea de verdad al hilo de su presentación de una lógica trascendental. Y hay que decir que aquí Kant esboza lo que la verdad no puede ser: a saber "el criterio meramente lógico de verdad (...) constituye una conditio sine qua non, esto es, una condición negativa de toda verdad. Pero la lógica no pasa de aquí" 43 . También del contenido hemos de tener información si queremos saber algo del objeto, pero "La lógica no nos suministra información alguna sobre el contenido del conocimiento, sino sólo sobre las condiciones formales de su conformidad con el entendimiento, condiciones que son completamente indiferentes respecto de los objetos"44. De modo que de los objetos nada podemos saber por el mero uso de las leyes de la lógica: nada podremos decir de los objetos con la simple lógica y cabe, por tanto, sospechar que se nos está remitiendo aquí a un terreno donde la verdad se asimila a "Saber qué es lo que hay que preguntar razonablemente", dado que parece estar clara "la imposibilidad de señalar un criterio de verdad que

\footnotetext{
39 H. Putnam. Cómo renovar la filosofía. Madrid: Cátedra,1994, 161.

40 H. Putnam. Op. cit., 55.

${ }^{41}$ H. Putnam. Renewing Philosophy The Gifford Lectures, Cambridge, Mass.: Harvard University Press 1990/ Cómo renovar la filosofía, 57.

42 H. Putnam. Pragmatism. An Open Question, Oxford: Blackwell, 1995/ El pragmatismo. Un debate abierto, Barcelona, Editorial Gedisa, 27. El contexto de la cita es la relectura de la idea de verdad en William James, contra el malentendido que la asimila sin más a lo que es conveniente.

43 Kant. $K r V$, 98, A 60, B 84.

44 Kant. $K r V,, 100$, A 61, B 86.
} 
sea, a la vez, suficiente y universal"45. A fuerza de atrevimiento, cabe sospechar que Kant está aquí en línea con la idea de que la verdad se explica por "cómo llegar a la verdad". Y esto es un asunto de reflexión.

Podemos reflexionar y preguntarnos qué pensamientos de los que hemos tenido eran verdaderos y cuáles no, y esta pregunta es muy distinta de la de, por ejemplo, si esos pensamientos colaboraron a nuestro bienestar 46 . Porque la primera cuestión es una cuestión filosófica y, como tal, no se resuelve por mucho que averigüemos acerca del funcionamiento del cerebro47: "Lo importante es lo siguiente: los seres humanos son criaturas reflexivas, capaces de pensar en su propia práctica y de criticarla desde diversos puntos de vista"48. Y, desde esta perspectiva, cabe decir que "la ciencia actual no proporciona ningún bosquejo de 'concepción absoluta del mundo", por lo que sigue en pie el problema de Kant de "explicar la relación referencial entre nuestras 'representaciones'y el mundo"49.

Estamos embarcados, entonces, en la misma tarea kantiana que se pregunta “CCómo podemos (...) aplicar la categoría a los fenómenos?” y que elabora para responder la doctrina del "Esquematismo de los conceptos puros del entendimiento"50. Y, resumiendo tal doctrina, "Será, pues, posible aplicar la categoría a los fenómenos por medio de la determinación trascendental del tiempo cuando tal aplicación permita, como esquema de los conceptos del entendimiento, subsumir los fenómenos bajo la categoría"51. Estamos, por tanto, ante el intento kantiano de dar solución al problema de la representación, "el acertijo planteado por Kant de cómo algo que hay en la mente puede ser representación de algo que está fuera de ella" 52 .

Parece claro que para Kant existe ese algo que está fuera de la mente: "Kant no duda de que hay alguna realidad independiente de la mente; para él es virtualmente un postulado de la razón (...) Pero quizá Kant esté en lo cierto, quizá no podamos dejar de pensar que hay, de algún modo, una "base" independiente de la mente para nuestra experiencia, aun cuando las tentativas de hablar de ella nos conduzca de inmediato al sin sentido"53. Esto parece particularmente claro si atendemos a las propias palabras de Kant: "La prueba requerida debe, pues, mostrar que tenemos experiencia de las cosas externas, no simple imaginación. Ello no podrá ocurrir más que en el caso de que podamos demostrar que nuestra misma experiencia interna

\footnotetext{
45 Kant. $K r V$, 97, A 58, y 98, A 59, respectivamente.

46 H. Putnam. Cómo renovar la filosofía, 65.

47 H. Putnam. Cómo renovar la filosofía, 56 y ss.

48 H. Putnam. Op. cit., 65.

49 H. Putnam. Op. cit., 73.

50 Kant. $K r V$, 182 y ss., A137, B176 y ss.

51 Kant. $K r V$, 183, A 139, B178.

52 H. Putnam. Op. cit., 70.

${ }^{53}$ H. Putnam. Razón, verdad e historia, 70-71.
} 
-indudable para Descartes- sólo es posible si suponemos la experiencia externa" 54 . Así, pues, es paradójicamente según esto el propio idealismo el que conduce al realismo, esto es, a la presuposición de la existencia del mundo externo que me confirma.

Este realismo no puede asimilarse con la pretensión representacionalista moderna de que las cosas externas nos son conocidas por la inferencia a partir de los sense data, o en otra versión más actual, a partir de los signos mentales o las palabras. Dicha pretensión parte de la correspondencia entre nuestras representaciones y el mundo, que sólo puede ser de una manera y que nunca es objeto de conocimiento directo. Los sense data, entre nuestro conocimiento y el mundo, compondrían el contenido incorregible de nuestro contacto perceptivo con las cosas. Esta versión del realismo metafísico postula que "Hay exactamente una descripción verdadera y completa de 'cómo es el mundo'. La verdad supone una especie de relación de correspondencia entre palabras o signos mentales y cosas o conjuntos de cosas externas. A esta perspectiva la llamaré externalista, ya que su punto de vista predilecto es el del Ojo de Dios" 55 . Ahora bien, ¿cómo situarnos en esa perspectiva?, ¿cómo dar cuenta de la correspondencia entre representaciones y mundo desde el otro lado de la mente? Porque dar cuenta de ello exige, por fuerza, situarse fuera de la mente, en las cosas mismas y esto, como lo ve Putnam, es una posición imposible para el sujeto de conocimiento carente de una visión omnisciente. Frente a esa perspectiva, como es sabido, Putnam defiende en Razón, verdad e historia una perspectiva que "carece de nombre que no sea ambiguo (...). La denominaré perspectiva internalista, ya que lo característico de tal concepción es sostener que sólo tiene sentido formular la pregunta ¿de qué objetos consta el mundo? desde dentro de una teoría o descripción" 56 .

Si entendemos descripción o teoría en sentido amplio, no otra cosa parece querer decir que "La reflexión (reflexio) no se ocupa de los objetos mismos, para recibir directamente de ellos los conceptos, sino que es el estado del psiquismo en el que nos disponemos a descubrir las condiciones subjetivas bajo las cuales podemos obtener conceptos" 57 . Y es posible este descubrimiento para Kant por medio de la "reflexión trascendental", que "contiene el fundamento de la posibilidad de comparar objetivamente las representaciones entre sí" 58 y, con ello, distinguir la facultad a la que "pertenecen los conceptos dados"59. Más allá de que tal cosa sea posible, ciertamente se nos está diciendo que contestar a "¿de qué objetos consta el

\footnotetext{
54 Kant. $K r V$, 247, B 275.

55 H. Putnam. Razón, verdad e historia, 58.

$56 \mathrm{H}$. Putnam. Ibid.

57 Kant. $\mathrm{KrV}$, 277, B 316.

58 Kant. $\mathrm{KrV}$, 278, B 319.

${ }^{59}$ Kant. $\mathrm{KrV}$, 277, B 317.
} 
mundo?" pasa por contestar a desde qué esquema conceptual lo aprehendo. Y en Putnam ese esquema es inseparable de los valores, puesto que "La decisión de que una imagen del mundo es verdadera (o verdadera según nuestros conocimientos actuales o "tan verdadera como la que más") y las respuestas a las cuestiones relevantes (así como nuestra capacidad para responderlas) revelan todo nuestro sistema de compromisos valorativos, sobre el cual descansan. Un ser sin valores tampoco tiene hechos"60.

Esta tesis putnamiana parece bifurcarse por completo del camino kantiano, ya que la objetividad (o la inter-subjetividad) de nuestras condiciones trascendentales de conocimiento excluye cualquier consideración que las vincule a los valores. Sin embargo, tomado en su conjunto el uso teórico de la razón en Kant apela y compromete a la dimensión moral-valorativa, por cuanto puede entenderse guiado por el interés práctico-moral. No otra cosa cabe desprender de las palabras del propio Kant, cuando por ejemplo escribe: "Consiguientemente, de haber un uso correcto de la razón pura, caso en el que tiene que haber también un canon de la misma, éste no se referirá al uso especulativo de la razón, sino que será un canon de su uso práctico"61.

La primacía del realismo pragmático se hace patente en Putnam a partir de sus consideraciones en Las mil caras del realismo. No se trata aquí de seguir esa evolución intelectual, ni mucho menos de hacer de Kant un pragmatista declarado. Pero, a modo de sugerencia, sí se quiere señalar cómo en ambos la dimensión práctica es la que hace comprensible y, ciertamente, compromete el uso teórico de la razón. En este aspecto parece Putnam sentirse muy cerca de Kant, cuando subraya que "Hay, a pesar de todo, otra faceta del pensamiento de Kant, un aspecto que se conecta inmediatamente con el pragmatismo, y que podríamos llamar la primacía de la razón práctica" 62 .

Como se ha tratado de mostrar, el realismo interno de Putnam es heredero directo de la moderna pregunta kantiana sobre "¿qué es el hombre”?. Que tal pregunta resuma todas las cuestiones filosóficas no debe entenderse, sin embargo, como que no se acepte que hay algo más que el hombre y que, en este sentido, la religión marca el límite de la razón humana. También Putnam ve en la religión el sentido de tal límite63.

La dirección kantiana en la filosofía de Putnam ha sido reconocida64, pero quizá se ha dado excesivamente por supuesto, sin detenerse en los lugares donde tal cosa es más explícita. Esta dirección puede leerse como una apuesta por una concepción

\footnotetext{
60 H. Putnam. Razón, verdad e historia, 199.

61 Kant. $\mathrm{KrV}, 625$, A 797, B 825.

62 H. Putnam. El pragmatismo. Un debate abierto, 64.

63 G. Borradori. The American Philosopher. Chicago: University of Chicago Press, 1994, 7

64 J. Nubiola. "Putnam, H.: Realism with a Human Face". Anuario Filosófico 24/2 (1991), 389-392, 390.
} 
de la objetividad pluralista, que no limite el sentido de la misma a la imposición de una sola versión de las cosas, sino que permita entender que "Lo que tenemos son versiones" mejores y peores y "en esto consiste la objetividad"65. Si no se acepta esta pluralidad para el caso de la objetividad misma, Putnam - como Kant mismopiensa que caemos en el peligro de adherirnos a un dogmatismo restrictivo.

La concepción putnamiana de la objetividad va de la mano de una concepción de la verdad que, como ya se ha dicho, la entiende como aceptabilidad racional ideal. Pero ha habido quien ha criticado que esta concepción está demasiado cerca de una que, como el mundo nouménico en Kant, parte del supuesto de que queda siempre una realidad trascendente y que no puede ser conceptualizada ${ }^{66}$. Esta consecuencia de la idea putnamiana de verdad puede leerse como un resto del idealismo de factura más netamente kantiana, pero también puede adquirir otro sentido: aquél por el cual, en sintonía con Rorty, estaríamos ante una concepción del conocimiento que entiende que éste no es representación o "espejo" de la naturaleza67. En este sentido, si aceptamos esta lectura, la posición de Putnam se separaría de la kantiana y, en general, de toda la filosofía moderna que mantuvo "un 'interior' que pueda contrastarse con algo (quizás algo muy diferente) "exterior"'68. El propio Putnam rechaza que tenga sentido preguntarse por la cosa en sí, como lo hace Kant, pues esta pregunta presupone que hay una manera objetiva de referirse al mundo, a un mundo que sería verdadero en sí mismo y más allá de nuestro esquema conceptual para referirnos a él. Pero "la noción de 'cosa en sí' no tiene sentido"69.

Ahora bien, Putnam también plantea que entendamos que Kant está proponiendo ahora una concepción de la verdad que no se traduce en la vieja fórmula de la correspondencia entre ideas y objetos: por el contrario, y en ruptura con esa concepción, se trataría de situar el conocimiento verdadero a caballo de nuestro esquema conceptual y de la realidad, cosa que, de aceptarse, reorienta la comprensión de la propuesta kantiana en la dirección de lo que Putnam considera el realismo interno ${ }^{70}$.

Si hablamos de aceptabilidad racional y de objetividad por relación a la misma, podemos preguntarnos qué queremos decir al afirmar que un enunciado es verdadero. Como es imposible establecer que nuestras ideas se correspondan con los hechos, una vez desechada la verdad como correspondencia, sólo podremos referirnos a las condiciones que permiten hablar de las condiciones de verdad para un enunciado: “(...) aprehendemos la verdad (justificación idealizada) tal y como aprehendemos cualquier otro concepto: por medio de una comprensión (en gran medi-

\footnotetext{
65 H. Putnam. Las mil caras del realismo, 147.

66 J. Folina. "Putnam, Realism and Truth". Synthese, 103 (1995), 141-152.

67 R. Rorty. Objetividad, relativismo y verdad, 29.

68 Ibidem.

69 H. Putnam. Op. cit., 87.

70 H. Putnam. Op. cit., 96.
} 
da implícita) de los factores que hacen racionalmente aceptable decir que algo es verdadero"71. Lo que hace "racionalmente aceptable decir que algo es verdadero" no es ni más ni menos que aceptar que hay una experiencia externa que sólo lo es si "los propios inputs sobre los que se basa nuestro conocimiento están conceptualmente contaminados. Pero es mejor tener inputs contaminados que no tener inputs de ninguna clase. Y si todo lo que tenemos son inputs contaminados, aun así no tenemos poco"72. Leamos de nuevo esta "contaminación conceptual" al hilo de las palabras kantianas: "(...) Todo conocimiento empírico de los objetos ha de conformarse forzosamente a esos conceptos, ya que, si dejamos de presuponerlos, nada puede ser objeto de la experiencia"73.

Cabe concluir que, tanto en Putnam como en Kant, experiencia y esquema conceptual se imbrican para dar cuenta de la objetividad del conocimiento. Que este esquema conceptual sea indisociable de los valores con el que lo pensamos es algo que aleja a Putnam de la concepción kantiana. Pero el núcleo principal de ese realismo, que se entiende como interno, es en ambos pensadores afín, como se ha tratado de mostrar aquí. Aun con su giro pragmatista posterior, Putnam seguirá manteniendo la validez general de esta posición del realismo interno, un realismo que suscribe la tesis kantiana conforme a la cual se trata de proponer "una concepción de la verdad que unifique los componentes objetivos y subjetivos. Esta concepción se retrotrae, al menos en su espíritu, a las ideas de Inmanuel Kant"74.

\section{Luisa Posada Kubissa}

Departamento de Teoría del Conocimiento,

Estética e Historia del Pensamiento

Universidad Complutense de Madrid

mlposada@filos.ucm.es

\footnotetext{
71 H. Putnam. Razón, verdad e historia, 127.

72 H. Putnam. Op. cit., 64.

${ }^{73}$ Kant. $K r V$, 126, B 126.

74 H. Putnam. Razón, verdad e historia, 11-12.
} 